\title{
Prognostic factors for mortality due to pneumonia among adults from different age groups in Singapore and mortality predictions based on PSI and CURB-65
}

\author{
Zoe Xiaozhu Zhang ${ }^{1}$, MBBS, PhD, Yang Yong ${ }^{2,3}, \mathrm{MBBS}, \mathrm{PhD}$, Wan C $\underline{\mathrm{Tan}}^{4}$, MD, FRCP, Liang $\underline{\operatorname{Shen}}^{5}$, PhD, Han Seong $\underline{\mathrm{Ng}}^{6}, \mathrm{MD}$,
} Kok Yong Fong ${ }^{3}, \mathrm{MD}$

\begin{abstract}
INTRODUCTION Pneumonia is associated with considerable mortality. However, there is limited information on agespecific prognostic factors for death from pneumonia.

METHODS Patients hospitalised with a diagnosis of pneumonia through the emergency department were stratified into three age groups: $18-64$ years, 65-84 years and $\geq 85$ years. Multivariate logistic regression and receiver operating characteristic curve analyses were conducted to evaluate prognostic factors for mortality and the performance of pneumonia severity scoring tools for mortality prediction.

RESULTS A total of 1,902 patients were enrolled (18-64 years: 614 [32.3\%]; 65-84 years: 944 [49.6\%]; $\geq 85$ years: 344 [18.1\%]). Mortality rates increased with age (18-64 years: $7.3 \% ; 65-84$ years: $16.1 \%$; $\geq 85$ years: $29.7 \% ; p<0.001$ ). Malignancy and tachycardia were prognostic of mortality among patients aged 18-64 years. Male gender, malignancy, congestive heart failure and eight other parameters reflecting acute disease severity were associated with mortality among patients aged 65-84 years. For patients aged $\geq 85$ years, altered mental status, tachycardia, blood urea nitrogen, hypoxaemia, arterial $\mathrm{pH}$ and pleural effusion were significantly predictive of mortality. The Pneumonia Severity Index (PSI) was more sensitive than CURB-65 (confusion, uraemia, respiratory rate $\geq 30$ per minute, low blood pressure, age $\geq 65$ years) for mortality prediction across all age groups.

CONCLUSION The predictive effect of prognostic factors for mortality varied among patients with pneumonia from the different age groups. PSI performed significantly better than CURB-65 for mortality prediction, but its discriminative power decreased with advancing age.
\end{abstract}

Keywords: CURB-65, mortality, pneumonia, pneumonia severity index, prognostic factor

\section{INTRODUCTION}

Community-acquired pneumonia (CAP), the most common infectious disease worldwide, is associated with considerable morbidity and mortality. It has a particularly high incidence and mortality rate among elderly people. ${ }^{(1-7)}$ Young and middleaged patients (aged $<65$ years) die from CAP as well, although the incidence rate is low. ${ }^{(8,9)}$ Many studies have examined the predictive risk factors of CAP mortality in adults. ${ }^{(10-13)}$ Increasing age, male gender, comorbidities and multilobar consolidation are often of prognostic significance. ${ }^{(14-17)}$ However, patients of different ages have distinct physiological characteristics, clinical presentations and treatment responses, and therefore age groupspecific prognostic factors of mortality may be more useful for the clinical management of pneumonia.

The Pneumonia Severity Index (PSI) and CURB-65 (confusion, uraemia, respiratory rate $\geq 30$ per minute, low blood pressure, age $\geq 65$ years) are the most commonly used clinical scoring tools for severity assessment and mortality prediction of pneumonia. ${ }^{(10,18-23)}$ Higher scores generally suggest more severe diseases and higher risk of death. The performance of these severity scoring tools, however, varies among subsets of patients of different ages. Underestimation of the risk of death with increasing age has often been reported. ${ }^{(24-26)}$
Pneumonia represents a significant healthcare issue in Singapore. It is the fifth most common cause of hospitalisation and the second principal cause of death. ${ }^{(27)}$ In 2014, pneumonia was the underlying cause that was responsible for approximately $19 \%$ of all deaths reported in the country. ${ }^{(28)}$ In the present study, we retrospectively analysed all admitted patients with CAP from three age groups (ages 18-64 years, $65-84$ years and $\geq 85$ years) to identify prognostic factors for mortality when they presented to the emergency department (ED). We also evaluated the performance of PSI and CURB-65 for mortality prediction among patients with CAP in Singapore.

\section{METHODS}

The study was performed at Singapore General Hospital, Singapore, a large tertiary hospital with more than 1,500 beds. All patients admitted to the hospital after presenting to the ED with a primary diagnosis of pneumonia between 1 January 2012 and 31 December 2013 were included for chart review. Patients were considered to have a primary diagnosis of pneumonia if they had an ICD-9-CM (International Classification of Diseases, 9th revision, Clinical Modification) code of 480.x to 487.x. Patients were stratified into three age groups: $18-64$ years, $65-84$ years

${ }^{1}$ Department of Clinical Epidemiology, Tan Tock Seng Hospital, ${ }^{2}$ Department of Epidemiology, ${ }^{3}$ Medical Board, Singapore General Hospital, Singapore, ${ }^{4} U B C$ James Hogg Research Centre, Heart Lung Institute, St Paul's Hospital, Canada, ${ }^{5}$ Biostatistics Unit, NUS Yong Loo Lin School of Medicine, National University Health System, ${ }^{6}$ CEO Office, Singapore General Hospital, Singapore

Correspondence: Dr Zoe Zhang Xiaozhu, Senior Epidemiologist, Department of Clinical Epidemiology, Tan Tock Seng Hospital, 11 Jalan Tan Tock Seng, Singapore 308433. zoe_zhang_xz@ttsh.com.sg 
and $\geq 85$ years. Ethical approval and waiver of informed consent was obtained from the SingHealth Centralised Institutional Review Board (2014/226/A). This study was funded by the SingHealth Foundation Research Grant (SHF/FG590S/2013). The 30-day mortality data was provided by the National Registry of Disease Office, Health Promotion Board, Singapore.

Pneumonia was defined as an acute infection of the lung parenchyma that is characterised by symptoms of acute respiratory infection and the presence of an acute pulmonary infiltrate on chest radiography or abnormal auscultatory findings. ${ }^{(29)}$ Patients who had human immunodeficiency virus infection, pulmonary tuberculosis or cystic fibrosis, or those on long-term immunosuppressant or steroid treatment were excluded, in view that these diseases entailed varying progression, clinical management and prognosis.

A total of 27 prognostic factors were evaluated. Among them, 20 variables were derived from the PSI scoring tool developed by Fine et al, ${ }^{(10)}$ including demographic factors (e.g. age and gender), comorbidities (e.g. malignancy, renal disease, liver disease, cerebrovascular disease and congestive heart disease), initial vital signs (e.g. altered mental status [AMS], temperature, pulse rate, respiratory rate and systolic blood pressure), laboratory test results (e.g. levels of blood urea nitrogen [BUN], blood glucose, serum sodium, haematocrit, blood oxygen and arterial $\mathrm{pH}$ ) and chest radiography findings (e.g. pleural effusion). In addition, eight other common chronic illnesses in the Singapore local population were evaluated, including ischaemic heart disease, chronic obstructive pulmonary disease, diabetes mellitus, hypertension, asthma, bronchiectasis, Parkinson's disease and dementia. ${ }^{(30)}$ Data on initial vital signs, laboratory test results and chest radiography findings were from the first readings taken in the ED.

The indices of PSI and CURB-65 were calculated according to the original studies. ${ }^{(10,19)}$ The primary outcome was all-cause mortality at 30 days after admission to the hospital. Data on intensive care unit admission and hospital length of stay was also recorded. Categorical variables were expressed as counts (percentage). Continuous variables were expressed as mean \pm standard deviation or median with 25 th-75th interquartile range $(\mathrm{IQR})$.

Differences in frequencies were compared using chi-square test. Mann-Whitney $U$ test or Kruskal-Wallis test was used to assess any differences in continuous variables that were not normally distributed. To evaluate the potential prognostic factors associated with mortality, univariate analysis was first performed using the chi-square test. Factors with $p<0.05$ were included into the multivariate logistic regression model. The goodnessof-fit was tested using Hosmer-Lemeshow goodness-of-fit test. Odds ratios (ORs) and 95\% confidence intervals (Cls) were presented. Factors with event frequency $<1.5 \%$ were excluded from the analysis. Standard sensitivity, specificity, positive predictive value and negative predictive value were calculated at various cut-offs for the PSI and CURB-65 scores. Receiver operating characteristic (ROC) curve analysis was performed to evaluate the discriminatory power of PSI and CURB-65 for

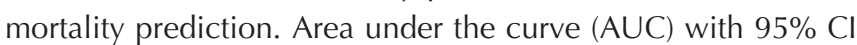

was computed for each age group of patients. All statistical tests were two-tailed and $p<0.05$ was considered to be statistically significant. All analyses were performed using IBM SPSS Statistics version 20 for Windows (IBM Corp, Armonk, NY, USA).

\section{RESULTS}

Baseline characteristics and clinical outcomes of patients across the three age groups are summarised in Table I. A total of 1,902 patients satisfied the study criteria, including 614 (32.3\%) patients aged $18-64$ years, 944 (49.6\%) patients aged $65-84$ years and $344(18.1 \%)$ patients aged $\geq 85$ years. The overall 30 -day mortality rate was $15.7 \%(\mathrm{n}=299)$, comprising $85.3 \%$ in-hospital deaths and $14.7 \%$ post-discharge deaths. Individual mortality rates for the three age groups were $7.3 \%, 16.1 \%$ and $29.7 \%$, respectively, for patients aged 18-64 years, 65-84 years and $\geq 85$ years $(p<0.001)$. Most of the evaluated comorbidities were less common among younger patients (aged 18-64 years), but had similar prevalence among patients aged 65-84 years and $\geq 85$ years. Liver disease was rare in our cohort (1.1\%). In terms of clinical presentation and laboratory test results, patients aged 65-84 years and $\geq 85$ years more frequently had AMS, respiratory rate $\geq 30$ /minute, and abnormal BUN, serum sodium and haematocrit levels at the time of ED admission. They also stayed significantly longer in hospital. The younger patients more frequently presented with tachycardia (pulse rate $\geq 125 /$ minute).

The association between prognostic factors and mortality were evaluated among the three age groups of patients (Tables II-IV). For patients aged 18-64 years, liver disease, Parkinson's disease and dementia, chronic obstructive pulmonary disease and AMS were excluded from the analysis because of low event frequencies. Eight factors with $p<0.05$ on univariate analysis were included in the multivariate logistic regression model. Malignancy and tachycardia showed an independent association with mortality, with ORs of 8.1 (IQR 4.0-16.6) and 4.3 (IQR 2.0-9.3), respectively (Table II). Among patients aged 65-84 years, 13 factors had $p<0.05$ on the chi-square test and were subsequently included in the multivariate logistic regression analysis. 11 of these factors showed a significant association with mortality, including male gender, malignancy, congestive heart failure, AMS, tachycardia, respiratory rate $\geq 30$ per minute, BUN $\geq 11 \mathrm{mmol} / \mathrm{L}$, serum sodium $<130 \mathrm{mmol} / \mathrm{L}$, hypoxaemia, arterial $\mathrm{pH}<7.35$ and pleural effusion (Table III). AMS (OR 3.3, 95\% CI 1.4-7.7), tachycardia (OR 3.2, 95\% Cl 1.8-5.6) and arterial pH $<7.35$ (OR 3.4, 95\% Cl 1.8-6.5) ranked among the top three factors showing a significant association with mortality. Among patients aged $\geq 85$ years, no comorbidities significantly increased the risk of death (Table IV). Asthma, however, showed a negative association with mortality among this group of patients (OR $0.1,95 \% \mathrm{Cl} 0.03-0.98 ; \mathrm{p}=0.047)$. Age, AMS (OR 6.1, 95\% Cl 2.1-17.3), tachycardia, $B U N \geq 11 \mathrm{mmol} / \mathrm{L}$, hypoxaemia, arterial $\mathrm{pH}<7.35$ and pleural effusion were independently associated with mortality in the final multivariate logistic regression analysis.

When patients were stratified into different severity classes according to PSI and CURB-65 scores, the mortality rates increased significantly with increasing severity levels (Table V). 
Table I. Baseline characteristics and clinical outcomes of patients with community-acquired pneumonia.

\begin{tabular}{|c|c|c|c|c|c|}
\hline \multirow[t]{3}{*}{ Variable } & \multicolumn{4}{|c|}{ No. (\%) } & \multirow[t]{3}{*}{ p-value } \\
\hline & \multirow{2}{*}{$\begin{array}{l}\text { Total } \\
(n=1,902)\end{array}$} & \multicolumn{3}{|c|}{ Age group } & \\
\hline & & $\begin{array}{l}18-64 \mathrm{yr} \\
(n=614)\end{array}$ & $\begin{array}{l}65-84 \text { yr } \\
(n=944)\end{array}$ & $\begin{array}{l}\geq 85 y r \\
(n=344)\end{array}$ & \\
\hline Age $(y r)^{*,+}$ & $73(61-82)$ & $54(42-60)$ & $76(71-80)$ & $88(86-92)$ & $<0.001$ \\
\hline Male gender & $1,056(55.5)$ & $370(60.3)$ & $517(54.8)$ & 169 (49.1) & 0.002 \\
\hline Malignancy & $348(18.3)$ & $98(16.0)$ & 197 (20.9) & $53(15.4)$ & 0.005 \\
\hline Cerebrovascular disease & $301(15.8)$ & $39(6.4)$ & $167(17.7)$ & $95(27.6)$ & $<0.001$ \\
\hline Renal dysfunction & $280(14.7)$ & $72(11.7)$ & $156(16.5)$ & $52(15.1)$ & 0.024 \\
\hline Congestive heart failure & $153(8.0)$ & $31(5.0)$ & $88(9.3)$ & $34(9.9)$ & 0.001 \\
\hline Liver disease & $21(1.1)$ & $7(1.1)$ & $11(1.2)$ & $3(0.9)$ & $>0.05$ \\
\hline Hypertension & $1,122(59.0)$ & $212(34.5)$ & $671(71.1)$ & $239(69.5)$ & $<0.001$ \\
\hline Ischaemic heart disease & $478(25.1)$ & $75(12.2)$ & $288(30.5)$ & $115(33.4)$ & $<0.001$ \\
\hline Parkinson's disease and dementia & $183(9.6)$ & $3(0.5)$ & $102(10.8)$ & $78(22.7)$ & $<0.001$ \\
\hline COPD & $112(5.9)$ & $8(1.3)$ & $70(7.4)$ & $34(9.9)$ & $<0.001$ \\
\hline Bronchiectasis & $61(3.2)$ & $16(2.6)$ & $29(3.1)$ & $16(4.7)$ & $>0.05$ \\
\hline Asthma & $137(7.2)$ & $53(8.6)$ & $62(6.6)$ & $22(6.4)$ & $>0.05$ \\
\hline \multicolumn{6}{|l|}{ Physical examination findings } \\
\hline Altered mental status & $65(3.4)$ & $7(1.1)$ & $34(3.6)$ & $24(7.0)$ & $<0.001$ \\
\hline Tachycardia (pulse rate $\geq 125 / \mathrm{min}$ ) & $205(10.8)$ & $80(13.0)$ & $91(9.6)$ & $34(9.9)$ & $>0.05$ \\
\hline Respiratory rate $\geq 30 / \mathrm{min}$ & $74(3.9)$ & $14(2.3)$ & $41(4.3)$ & $19(5.5)$ & 0.018 \\
\hline Systolic blood pressure $<90 \mathrm{mmHg}$ & $84(4.4)$ & $26(4.2)$ & $42(4.4)$ & $16(4.7)$ & $>0.05$ \\
\hline Temperature $<35^{\circ} \mathrm{C}$ or $\geq 40^{\circ} \mathrm{C}$ & $88(4.6)$ & $30(4.9)$ & $39(4.1)$ & $19(5.5)$ & $>0.05$ \\
\hline \multicolumn{6}{|l|}{ Laboratory and radiologic findings } \\
\hline Blood glucose $\geq 14 \mathrm{mmol} / \mathrm{L}$ & $177(9.3)$ & $55(9.0)$ & $99(10.5)$ & $23(6.7)$ & $>0.05$ \\
\hline Serum sodium $<130 \mathrm{mmol} / \mathrm{L}$ & $378(19.9)$ & $103(16.8)$ & $193(20.4)$ & $82(23.8)$ & 0.012 \\
\hline Haematocrit $<30 \%$ & $344(18.1)$ & $87(14.2)$ & $178(18.9)$ & $79(23.0)$ & 0.002 \\
\hline Hypoxaemia $\left(\mathrm{PaO}_{2}<60 \mathrm{mmHg}\right.$ or $\left.\mathrm{SaO}_{2}<90 \%\right)$ & $238(12.5)$ & $62(10.1)$ & $127(13.5)$ & $49(14.2)$ & $>0.05$ \\
\hline Arterial $\mathrm{pH}<7.35$ & $119(6.3)$ & $30(4.9)$ & $63(6.7)$ & $26(7.6)$ & $>0.05$ \\
\hline Pleural effusion & $671(35.3)$ & $188(30.6)$ & $344(36.4)$ & $139(40.4)$ & 0.05 \\
\hline \multicolumn{6}{|l|}{ Outcome parameter } \\
\hline 30-day mortality & $299(15.7)$ & $45(7.3)$ & $152(16.1)$ & $102(29.7)$ & $<0.001$ \\
\hline ICU admission & $111(5.8)$ & $37(6.0)$ & $67(7.1)$ & $7(2.0)$ & 0.002 \\
\hline Ventilation & $106(5.6)$ & $33(5.4)$ & $66(7.0)$ & $7(2.0)$ & 0.002 \\
\hline Hospital LOS (day) ${ }^{*,+}$ & $4(2-8)$ & $3(2-6)$ & $5(3-9)$ & $5(3-9)$ & $<0.001$ \\
\hline
\end{tabular}

*Data presented as median (interquartile range). +Differences in age and hospital length of stay were compared using non-parametric Kruskal-Wallis test and difference in frequencies was assessed using chi-square test. COPD: chronic obstructive pulmonary disease; ICU: intensive care unit; LOS: length of stay; PaO ${ }_{2}$ : arterial partial pressure of oxygen; $\mathrm{SaO}_{2}$ : blood oxygen saturation

However, the 30-day mortality of PSI Class III among patients aged 18-64 years was significantly higher than that in the other two age groups (18-64 years: $7.5 \%$; $65-84$ years: $2.1 \%$; $\geq 85$ years: $2.6 \%, \mathrm{p}<0.001)$. Patients with CURB-65 score 1 had 30 -day mortality rates in the range $8.9 \%-14.1 \%$.

The sensitivity, specificity, positive predictive value and negative predictive value of PSI and CURB-65 for predicting 30-day mortality for each age group are shown in Table VI. In general, PSI was more sensitive than CURB-65 for mortality prediction among patients with CAP. Among patients aged 18-64 years, the sensitivity of PSI had a big drop from $100 \%$ to $80 \%$ at the Class IV cut-off, whereas it remained at $97 \%$ and
$99 \%$, respectively, in the other two patient groups. ROC curve analysis revealed a trend of decreasing accuracy in relation to higher age categories for both PSI and CURB-65 (Fig. 1). The AUC of PSI appeared higher than that of CURB-65 in each age group.

\section{DISCUSSION}

In this study, we defined predictive risk factors for mortality in three age-specific groups of patients with pneumonia in Singapore. Among patients aged 18-64 years, malignancy and tachycardia (pulse rate $\geq 125$ per minute) were significantly associated with mortality. A total of 11 factors were prognostic for mortality among patients aged 65-84 years, including malignancy, congestive 
Table II. Association of prognostic factors with mortality among patients with pneumonia aged 18-64 years $(\mathrm{n}=614)$.

\begin{tabular}{|c|c|c|c|c|c|}
\hline \multirow[t]{2}{*}{ Variable } & \multicolumn{2}{|c|}{ Mortality [No. (\%)] } & \multirow{2}{*}{$\begin{array}{c}\text { Univariate } \\
\text { analysis } \\
\text { p-value }\end{array}$} & \multicolumn{2}{|c|}{$\begin{array}{l}\text { Multivariate logistic } \\
\text { regression analysis }\end{array}$} \\
\hline & Yes $(n=45)$ & No $(n=569)$ & & p-value & OR $(95 \% \mathrm{CI})$ \\
\hline Age (yr)* & $58(48-62)$ & $54(42-60)$ & $0.079+$ & - & - \\
\hline Male gender & $33(73.3)$ & $337(59.2)$ & 0.063 & - & - \\
\hline \multicolumn{6}{|l|}{ Coexisting illness } \\
\hline Malignancy & $26(57.8)$ & $72(12.7)$ & $<0.001$ & $<0.001$ & $8.1(4.0-16.6)$ \\
\hline Cerebrovascular disease & $5(11.1)$ & $34(6.0)$ & 0.17 & - & - \\
\hline Renal dysfunction & $5(11.1)$ & $67(11.8)$ & 0.89 & - & - \\
\hline Congestive heart failure & $1(2.2)$ & $30(5.3)$ & 0.72 & - & - \\
\hline Liver disease & $0(0)$ & $7(1.2)$ & - & - & - \\
\hline Hypertension & $15(33.3)$ & $197(34.6)$ & 0.86 & - & - \\
\hline Diabetes mellitus & $7(15.6)$ & $129(22.7)$ & 0.27 & - & - \\
\hline Ischaemic heart disease & $8(17.8)$ & $67(11.8)$ & 0.24 & - & - \\
\hline Parkinson's disease and dementia & $1(2.2)$ & $2(0.4)$ & - & - & - \\
\hline COPD & $0(0)$ & $8(1.4)$ & - & - & - \\
\hline Bronchiectasis & $2(4.4)$ & $14(2.5)$ & 0.33 & - & - \\
\hline Asthma & $1(2.2)$ & $52(9.1)$ & 0.16 & - & - \\
\hline \multicolumn{6}{|l|}{ Physical examination findings } \\
\hline Altered mental status & $0(0)$ & $7(1.2)$ & - & - & - \\
\hline Tachycardia (pulse rate $\geq 125 / \mathrm{min}$ ) & $19(42.2)$ & $61(10.7)$ & $<0.001$ & $<0.001$ & $4.3(2.0-9.3)$ \\
\hline Respiratory rate $\geq 30 / \mathrm{min}$ & $3(6.7)$ & $11(1.9)$ & 0.08 & - & - \\
\hline Systolic blood pressure $<90 \mathrm{mmHg}$ & $6(13.3)$ & $20(3.5)$ & 0.002 & 0.21 & $2.3(0.6-8.2)$ \\
\hline Temperature $<35^{\circ} \mathrm{C}$ or $\geq 40^{\circ} \mathrm{C}$ & $2(4.4)$ & $28(4.9)$ & 0.89 & - & - \\
\hline \multicolumn{6}{|l|}{ Laboratory and chest radiography findings } \\
\hline Blood urea nitrogen $\geq 11 \mathrm{mmol} / \mathrm{L}$ & $14(31.1)$ & $70(12.3)$ & $<0.001$ & 0.13 & $2.0(0.8-4.9)$ \\
\hline Blood glucose $\geq 14 \mathrm{mmol} / \mathrm{L}$ & $5(11.1)$ & $50(8.8)$ & 0.60 & - & - \\
\hline Serum sodium $<130 \mathrm{mmol} / \mathrm{L}$ & $15(33.3)$ & $88(15.5)$ & 0.002 & 0.84 & $1.1(0.5-2.4)$ \\
\hline Haematocrit $<30 \%$ & $10(22.2)$ & $77(13.5)$ & 0.11 & - & - \\
\hline Hypoxaemia $\left(\mathrm{PaO}_{2}<60 \mathrm{mmHg}\right.$ or $\left.\mathrm{SaO}_{2}<90 \%\right)$ & $13(28.9)$ & $49(8.6)$ & $<0.001$ & 0.14 & $1.9(0.8-4.5)$ \\
\hline Arterial $\mathrm{pH}<7.35$ & $10(22.2)$ & $20(3.5)$ & $<0.001$ & 0.05 & $2.8(1.0-8.2)$ \\
\hline Pleural effusion & $21(46.7)$ & $167(29.3)$ & 0.017 & 0.22 & $1.6(0.8-3.4)$ \\
\hline
\end{tabular}

Univariate analysis was performed to assess the association between each individual prognostic factor and mortality. Factors with $p<0.05$ were included in the binary logistic regression model. Hosmer-Lemeshow goodness-of-fit test, $\chi^{2}=2.2, \mathrm{df}=4, \mathrm{p}=0.696$. ${ }^{*}$ Data presented as median (interquartile range). $+\mathrm{Difference} \mathrm{in}$ age was examined using Mann-Whitney $U$ test and difference in frequencies was examined using chi-square test. Cl: confidence interval; COPD: chronic obstructive pulmonary disease; OR: odds ratio; $\mathrm{PaO}_{2}$ : arterial partial pressure of oxygen; $\mathrm{SaO}_{2}$ : blood oxygen saturation
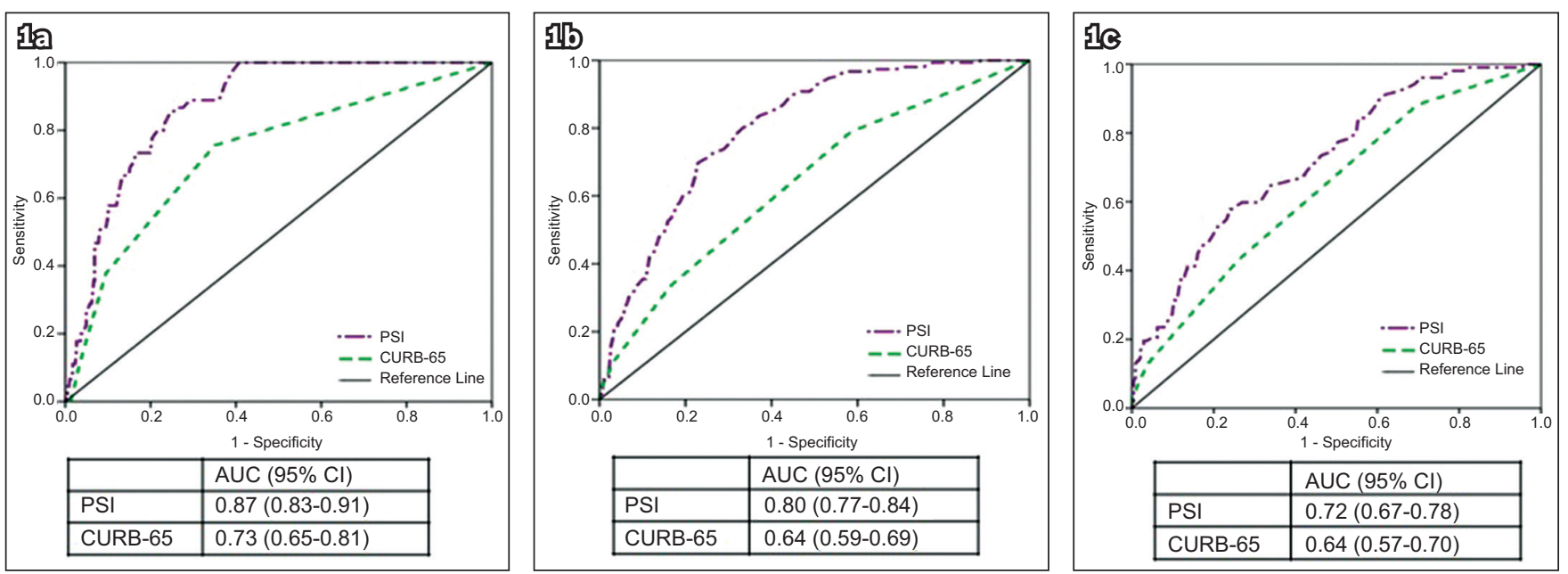

Fig. 1 Receiver operating characteristic curves show PSI and CURB-65 with respect to prediction of 30-day mortality for patients with pneumonia aged (a) 18-64 years, (b) 65-84 years and (c) $\geq 85$ years. AUC: area under the curve; Cl: confidence interval; CURB-65: confusion, uraemia, respiratory rate $\geq 30$ per minute, low blood pressure, age $\geq 65$ years; PSI: Pneumonia Severity Index 
Table III. Association of risk factors with mortality among patients with pneumonia aged 65-84 years $(\mathrm{n}=944)$.

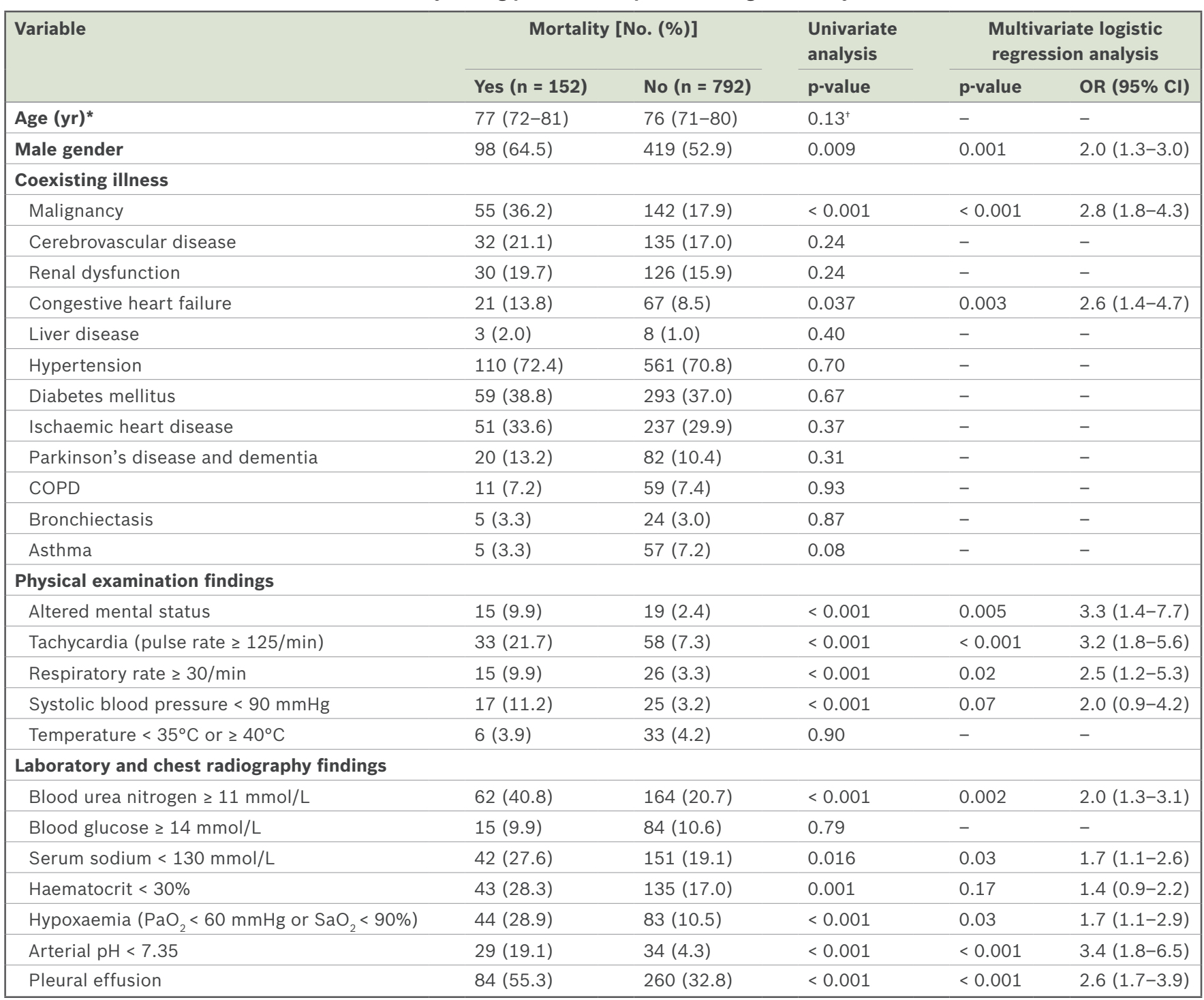

Univariate analysis was performed to assess the association between each individual prognostic factor and mortality. Factors with $p<0.05$ were included in the binary logistic regression model. Hosmer-Lemeshow goodness-of-fit test, $\chi^{2}=3.2, \mathrm{df}=8, p=0.922 .{ }^{*}$ Data presented as median (interquartile range). + Difference in age was examined using Mann-Whitney $U$ test and difference in frequencies was examined using chi-square test. Cl: confidence interval; COPD: chronic obstructive pulmonary disease; OR: odds ratio; $\mathrm{PaO}_{2}$ : arterial partial pressure of oxygen; $\mathrm{SaO}_{2}$ : blood oxygen saturation

heart failure, male gender and eight other parameters reflecting initial vital signs and abnormal laboratory results. For patients aged $\geq 85$ years, age, initial vital signs and abnormal laboratory test results were critical for mortality prediction.

Increasing age has been defined as a predictive factor for mortality in pneumonia patients in many studies, especially among patients aged 65 years or older. ${ }^{(10,19,31)}$ In our study, age significantly increased the risk of death only among patients aged $\geq 85$ years. Conte et al, who analysed more than 2,000 patients aged $\geq 65$ years, suggested that age $\geq 85$ years was an independent predictive factor for mortality. ${ }^{(32)}$ Calle et al reported that age $\geq 90$ years was markedly associated with mortality. ${ }^{(33)}$ Ageing is associated with a progressively weakened immune system and decreased lung performance. For patients of extreme age ( $\geq 85$ years in our study), these changes alone are probably drastic, which independently increases the risk of death due to pneumonia.
Comorbid condition is another well-recognised risk factor for death due to pneumonia. ${ }^{(8,34)}$ Fine et al have defined the significant prognostic value of five types of chronic illnesses as per PSI among patients of all ages, including malignancy, liver disease, renal disease, congestive heart failure and cerebrovascular disease. ${ }^{(10)}$ Marrie et al studied over 11,000 Canadian patients aged 18-55 years and depicted a similar spectrum of chronic illnesses associated with pneumonia death. ${ }^{(34)}$ Among the 13 comorbidities evaluated in this study, only malignancy and congestive heart failure were significantly predictive of mortality among patients aged 18-64 years and/or 65-84 years. Most of the chronic diseases studied were common among patients aged $\geq 85$ years. However, none were independently associated with greater mortality. It is known that the prognosis of a disease in elderly people is often determined by the patient's overall health status. ${ }^{(14,35,36)}$ It is very likely that coexisting chronic diseases work in a synergic manner, affecting patients' general health condition 
Table IV. Association of risk factors with mortality among patients with pneumonia aged $\geq 85$ years $(\mathrm{n}=344)$.

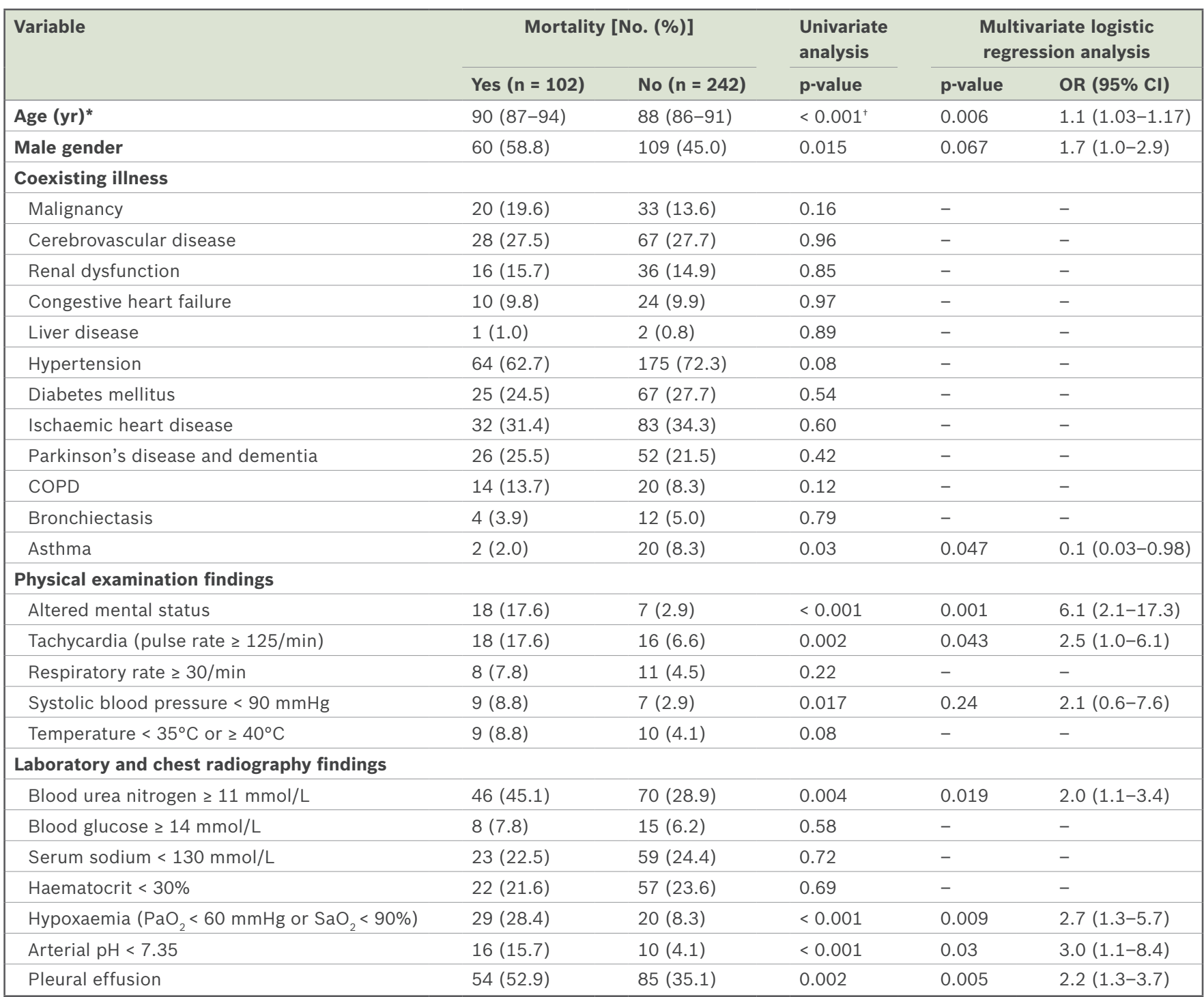

Univariate analysis was performed to assess the association between each individual prognostic factor and mortality. Factors with $p<0.05$ were included in the binary logistic regression model. Hosmer-Lemeshow goodness-of-fit test, $\chi^{2}=9.4, d f=8, p=0.31$. ${ }^{*}$ Data presented as median (interquartile range). + Difference in age was examined using Mann-Whitney $U$ test and difference in frequencies was assessed using chi-square test. Cl: confidence interval; COPD: chronic obstructive pulmonary disease; OR: odds ratio; $\mathrm{PaO}_{2}$ : arterial partial pressure of oxygen; $\mathrm{SaO}_{2}$ : blood oxygen saturation

and increasing the severity of disease and the mortality rate, although they are not independently associated with death. We also noticed the increasing trend of malignancy, Parkinson's disease and dementia, and chronic obstructive pulmonary disease among the non-survivors aged $\geq 85$ years in our study. A study with a larger sample size would give a more definite conclusion.

In particular, asthma showed a negative association with mortality among patients with pneumonia aged $\geq 85$ years. Asthma is a known risk factor of pneumonia. ${ }^{(37)}$ Asthmatic patients with CAP have been reported to present earlier to the hospital, are more often given antibiotic treatment before hospital admission, and generally have low CAP severity. ${ }^{(38,39)}$ All these may indicate that these patients are more aware of respiratory problems, even when symptoms are mild, and actively seek medical care earlier during the course of disease. In contrast, non-asthmatic elderly patients may not be aware of the symptoms of CAP as early as asthmatics, causing a subsequent delay in diagnosis, admission and treatment, thus resulting in higher mortality.

Initial vital signs and the results of basic laboratory tests and chest radiography are critical information that is required for clinicians to rapidly understand patients' health condition, in particular the severity of acute illness and how well the body copes with it. In this study, AMS, increased BUN, hypoxaemia and pleural effusion were significantly associated with mortality among patients aged $65-84$ years and $\geq 85$ years, which was consistent with the findings of Fine et al. ${ }^{(10)}$ The non-survivors among patients aged 18-64 years also more frequently had increased BUN, hypoxaemia and pleural effusion, but the difference did not reach statistical significance.

Young patients rarely presented with AMS. However, AMS appeared to be a strong predictor for mortality among the two older patient groups, increasing the risk of death by 3.3 and 6.1 times, respectively. Infection has been reported as one of 
Table V. Mortality in PSI and CURB-65 severity classes among different age groups.

\begin{tabular}{|c|c|c|c|c|c|c|}
\hline \multirow[t]{3}{*}{ Category } & \multicolumn{6}{|c|}{ No. (\%) } \\
\hline & \multicolumn{2}{|c|}{$18-64 \mathrm{yr}$} & \multicolumn{2}{|c|}{$65-84 \mathrm{yr}$} & \multicolumn{2}{|c|}{$\geq 85 \mathrm{yr}$} \\
\hline & $\begin{array}{l}\text { Total } \\
(n=614)\end{array}$ & $\begin{array}{l}\text { 30-day } \\
\text { mortality }\end{array}$ & $\begin{array}{l}\text { Total } \\
(\mathrm{n}=944)\end{array}$ & $\begin{array}{l}\text { 30-day } \\
\text { mortality }\end{array}$ & $\begin{array}{l}\text { Total } \\
(n=344)\end{array}$ & $\begin{array}{l}\text { 30-day } \\
\text { mortality }\end{array}$ \\
\hline \multicolumn{7}{|c|}{ PSI risk class } \\
\hline I & $173(28.2)$ & $0(0)$ & $0(0)$ & $0(0)$ & $0(0)$ & $0(0)$ \\
\hline III & 120 (19.5) & $9(7.5)$ & $242(25.6)$ & $5(2.1)$ & $38(11.0)$ & $1(2.6)$ \\
\hline IV & $107(17.4)$ & $27(25.2)$ & $436(46.2)$ & $73(16.7)$ & $184(53.5)$ & $41(22.3)$ \\
\hline V & $33(5.4)$ & $9(27.3)$ & $185(19.6)$ & $74(40.0)$ & $121(35.2)$ & $60(49.6)$ \\
\hline \multicolumn{7}{|c|}{ CURB-65 score } \\
\hline 0 & 381 (62.1) & $11(2.9)$ & $1(0.1)$ & $0(0)$ & $0(0)$ & $0(0)$ \\
\hline 1 & $162(26.4)$ & $17(10.5)$ & $360(38.1)$ & $32(8.9)$ & $85(24.7)$ & $12(14.1)$ \\
\hline 3 & $17(2.8)$ & $5(29.4)$ & $139(14.7)$ & $34(24.5)$ & $85(24.7)$ & $31(36.5)$ \\
\hline 4 & $6(1.0)$ & $0(0)$ & $38(4.0)$ & $13(34.2)$ & $19(5.5)$ & $10(52.6)$ \\
\hline 5 & $1(0.2)$ & $0(0)$ & $5(0.5)$ & $4(80.0)$ & $3(0.9)$ & $3(100.0)$ \\
\hline
\end{tabular}

CURB-65: confusion, uraemia, respiratory rate $\geq 30$ per min, low blood pressure, age $\geq 65$ years; PSI: Pneumonia Severity Index

Table VI. Sensitivity, specificity, positive predictive value and negative predictive value for the prediction of 30 -day mortality at different cut-offs of PSI and CURB-65.

\begin{tabular}{|c|c|c|c|c|c|c|c|c|c|c|c|c|}
\hline \multirow[t]{2}{*}{ Category } & \multicolumn{4}{|c|}{$18-64 \mathrm{yr}$} & \multicolumn{4}{|c|}{$65-84$ yr } & \multicolumn{4}{|c|}{$\geq 85 \mathrm{yr}$} \\
\hline & Sensitivity & Specificity & PPV & NPV & Sensitivity & Specificity & PPV & NPV & Sensitivity & Specificity & PPV & NPV \\
\hline \multicolumn{13}{|l|}{$\begin{array}{l}\text { PSI risk } \\
\text { class }\end{array}$} \\
\hline$\geq 1$ & 100 & 0 & 7 & - & - & - & - & - & - & - & - & - \\
\hline$\geq \mathrm{II}$ & 100 & 30 & 10 & 100 & 100 & 0 & 16 & - & 100 & 0 & 30 & - \\
\hline$\geq \mathrm{III}$ & 100 & 56 & 15 & 100 & 100 & 10 & 18 & 100 & 100 & 0 & 30 & 100 \\
\hline$\geq I V$ & 80 & 77 & 22 & 98 & 97 & 40 & 24 & 98 & 99 & 16 & 33 & 97 \\
\hline$\geq V$ & 20 & 96 & 27 & 94 & 49 & 86 & 40 & 90 & 59 & 75 & 50 & 81 \\
\hline \multicolumn{13}{|l|}{$\begin{array}{l}\text { CURB-65 } \\
\text { score }\end{array}$} \\
\hline$\geq 0$ & 100 & 0 & 7 & - & 100 & 0 & 16 & - & - & - & - & - \\
\hline$\geq 1$ & 76 & 65 & 15 & 97 & 100 & 0 & 16 & 100 & 100 & 0 & 30 & - \\
\hline$\geq 3$ & 11 & 97 & 21 & 93 & 60 & 17 & 12 & 68 & 43 & 74 & 41 & 76 \\
\hline$\geq 4$ & 0 & 99 & 0 & 93 & 11 & 97 & 40 & 85 & 13 & 96 & 59 & 72 \\
\hline$\geq 5$ & 0 & 100 & 0 & 93 & 3 & 100 & 80 & 84 & 3 & 100 & 100 & 71 \\
\hline
\end{tabular}

CURB-65: confusion, uraemia, respiratory rate $\geq 30$ per minute, low blood pressure, age $\geq 65$ years; NPV: negative predictive value; PPV: positive predictive value; PSI: Pneumonia Severity Index

the commonest causes for AMS in the ED. One in nine elderly patients presenting with AMS are reported to die during their hospital stay. ${ }^{(40)}$ Therefore, timely diagnosis and intervention is critical. Accurate assessment, however, can be challenging when the change of mental status is subtle and the patients are very elderly. ${ }^{(41)}$

Tachycardia and acidosis (arterial $\mathrm{pH}<7.35$ ) were independently associated with mortality among all three patient groups. Although tachycardia is usually a nonspecific clinical presentation that can be influenced by many factors, it is associated with the severity of pneumonia and often appears ahead of other severe clinical presentations. ${ }^{(10,42,43)}$ Physicians probably need to be alert to the occurrence of tachycardia in patients with pneumonia, and close monitoring and aggressive clinical management may be necessary. Acidosis is usually associated with central nervous system malfunctions, with patients likely to become disoriented or comatose; therefore, acute treatment is critical.

PSI and CURB-65 are the most well-validated risk prediction models of CAP. PSI performs better than CURB-65 among patients in Singapore. ${ }^{(4)}$ In our study, PSI was more accurate than CURB-65 for severity stratification. However, it was worth noting that PSI Class III, which was defined as a low-risk class of death in the original study, ${ }^{(10)}$ unexpectedly had a mortality rate of $7.5 \%$ among patients aged 18-64 years in our study. Other researchers have also reported that PSI could incorrectly categorise young 
patients with severe pneumonia into low-risk classes due to the inappropriate weight accorded to age. ${ }^{(25,45)}$ The ROC analysis in our study revealed that the best PSI cut-off score for mortality prediction was about 85-90 for younger patients, which was equivalent to PSI Class III (data not shown). Therefore, taking PSI Class III as a low-risk class of death may not be appropriate for the younger patient groups. On the contrary, elderly patients in the low PSI severity classes would most likely survive within 30 days of admission. This was demonstrated in a recent study conducted among a group of patients with healthcare-associated pneumonia and a median age of 80 years. ${ }^{(46)}$ As to mortality prediction, PSI showed higher sensitivity than CURB-65 for every age group. However, its power of discrimination decreased with advancing age. Chen et al have reported similar findings and believed that the excessive weight given to a patient's age leads to overestimation of disease severity among elderly patients with pneumonia. ${ }^{(25)}$

High hospital admission rate and high mortality rate are the two major characteristics of CAP in Singapore. ${ }^{(44)}$ In our study, over $85 \%$ of death among patients with pneumonia occurred in hospital. Therefore, the medical care these patients receive in hospital is one of the critical factors that is closely associated with their final clinical outcome. As the prognostic factors evaluated here are all readily available when patients visit EDs, clear awareness of these factors and understanding of their predictive value would help physicians to predict the clinical outcome and customise the medical care being provided. For younger patients aged 18-64 years, malignancy stood out as a strong predictive factor for mortality, as it increased the odds of death by 8.1 times. These findings suggest that close monitoring and intensive clinical intervention are most likely indispensable, even if the PSI severity level is not high. For patients aged $\geq 85$ years, severity in the acute phase of the disease was strongly associated with mortality. Elderly patients with pneumonia may clinically present only with delirium or acute confusion instead of respiratory signs or symptoms. However, a change of mental state is critical in forecasting the high risk of death not long after. Physicians probably need to explain and discuss the potential adverse outcome with family members while tailoring medical treatment and clinical management strategies.

This study had several limitations. First, it had a retrospective design. We extracted pre-existing data from patients' case notes, which might not be as accurate as data collected prospectively by means of direct interview or questionnaire. Second, we were unable to assess the variables that were not available in the medical records, even though they might have been important to the study. Third, our study may have been underpowered with regard to the detection of some associations due to the inadequacy of sample size for subgroup analyses.

In conclusion, the risk factors for mortality in pneumonia patients were not the same across different age groups. PSI was more accurate for mortality prediction than CURB-65. However, its discriminative power decreased with advancing age among patients with pneumonia.

\section{ACKNOWLEDGEMENTS}

We are grateful for the diligent work done by Ms Michelle Liu Ping, Research Coordinator, Department of Epidemiology, Medical Board, Singapore General Hospital, in the process of patient case note review.

\section{REFERENCES}

1. Jackson ML, Nelson JC, Jackson LA. Risk factors for community-acquired pneumonia in immunocompetent seniors. J Am Geriatr Soc 2009; 57:882-8.

2. Koivula I, Stén M, Mäkelä PH. Prognosis after community-acquired pneumonia in the elderly: a population-based 12-year follow-up study. Arch Intern Med 1999; 159:1550-5.

3. Meehan TP, Fine MJ, Krumholz HM, et al. Quality of care, process, and outcomes in elderly patients with pneumonia. JAMA 1997; 278:2080-4.

4. Marrie TJ, Haldane EV, Faulkner RS, Durant H, Kwan C. Community-acquired pneumonia requiring hospitalization. Is it different in the elderly? J Am Geriatr Soc $1985 ; 33: 671-80$

5. Riquelme R, Torres A, El-Ebiary M, et al. Community-acquired pneumonia in the elderly: a multivariate analysis of risk and prognostic factors. Am J Respir Crit Care Med 1996; 154:1450-5.

6. Venkatesan P, Gladman J, Macfarlane JT, et al. A hospital study of community acquired pneumonia in the elderly. Thorax 1990; 45:254-8.

7. Cillóniz C, Polverino E, Ewig S, et al. Impact of age and comorbidity on cause and outcome in community-acquired pneumonia. Chest 2013; 144:999-1007.

8. Simpson JC, Macfarlane JT, Watson J, Woodhead MA. A national confidential enquiry into community acquired pneumonia deaths in young adults in England and Wales. British Thoracic Society Research Committee and Public Health Laboratory Service. Thorax 2000; 55:1040-5.

9. Trotter CL, Stuart JM, George R, Miller E. Increasing hospital admissions for pneumonia, England. Emerg Infect Dis 2008; 14:727-33.

10. Fine MJ, Auble TE, Yealy DM, et al. A prediction rule to identify low-risk patients with community-acquired pneumonia. N Engl J Med 1997; 336:243-50.

11. Farr BM, Sloman AJ, Fisch MJ. Predicting death in patients hospitalized for community-acquired pneumonia. Ann Intern Med 1991; 115:428-36.

12. Fine MJ, Orloff JJ, Arisumi D, et al. Prognosis of patients hospitalized with community-acquired pneumonia. Am J Med 1990; 88:1N-8N.

13. Fine MJ, Smith MA, Carson CA, et al. Prognosis and outcomes of patients with community-acquired pneumonia. A meta-analysis. JAMA 1996; 275:134-41.

14. Marrie TJ, Wu L. Factors influencing in-hospital mortality in community-acquired pneumonia: a prospective study of patients not initially admitted to the ICU. Chest 2005; 127:1260-70.

15. Mortensen EM, Coley CM, Singer DE, et al. Causes of death for patients with community-acquired pneumonia: results from the Pneumonia Patient Outcomes Research Team cohort study. Arch Intern Med 2002; 162:1059-64.

16. Metersky ML, Waterer G, Nsa W, Bratzler DW. Predictors of in-hospital vs postdischarge mortality in pneumonia. Chest 2012; 142:476-81.

17. Wilson PA, Ferguson J. Severe community-acquired pneumonia: an Australian perspective. Intern Med J 2005; 35:699-705.

18. Aujesky D, Auble TE, Yealy DM, et al. Prospective comparison of three validated prediction rules for prognosis in community-acquired pneumonia. Am J Med 2005; 118:384-92.

19. Lim WS, van der Eerden MM, Laing R, et al. Defining community acquired pneumonia severity on presentation to hospital: an international derivation and validation study. Thorax 2003; 58:377-82.

20. Huang DT, Weissfeld LA, Kellum JA, et al. Risk prediction with procalcitonin and clinical rules in community-acquired pneumonia. Ann Emerg Med 2008; 52:48-58 e2.

21. Capelastegui A, España PP, Quintana JM, et al. Validation of a predictive rule for the management of community-acquired pneumonia. Eur Respir J 2006; 27:151-7.

22. Man SY, Lee N, Ip M, et al. Prospective comparison of three predictive rules for assessing severity of community-acquired pneumonia in Hong Kong. Thorax 2007; 62:348-53.

23. Menéndez R, Martinez R, Reyes $S$, et al. Biomarkers improve mortality prediction by prognostic scales in community-acquired pneumonia. Thorax 2009; 64:587-91.

24. Parsonage M, Nathwani D, Davey P, Barlow G. Evaluation of the performance of CURB-65 with increasing age. Clin Microbiol Infect 2009; 15:858-64.

25. Chen JH, Chang SS, Liu JJ, et al. Comparison of clinical characteristics and performance of pneumonia severity score and CURB-65 among younger adults, elderly and very old subjects. Thorax 2010; 65:971-7.

26. Mody L, Sun R, Bradley S. Community-acquired pneumonia in older veterans: does the pneumonia prognosis index help? J Am Geriatr Soc 2002; 50:434-8.

27. Ministry of Health, Singapore. Top 10 Conditions of Hospitalisation 2015. Available at: https://www.moh.gov.sg/content/moh_web/home/statistics/ Health_Facts_Singapore/Top_10_Conditions_of_Hospitalisation.html. Accessed 
February 5, 2016.

28. Ministry of Health, Singapore. Principal causes of death 2015. Available from: https://www.moh.gov.sg/content/moh_web/home/statistics/Health_Facts_ Singapore/Principal_Causes_of_Death.html. Accessed February 5, 2016.

29. Bartlett JG, Dowell SF, Mandell LA, et al. Practice guidelines for the management of community-acquired pneumonia in adults. Infectious Diseases Society of America. Clin Infect Dis 2000; 31:347-82.

30. Health Promotion Board, Singapore. Chronic Disease Management 2015. Available from: http://www.hpb.gov.sg/HOPPortal/health-article/ HPBSUEXTAPP1_4022097. Accessed February 12, 2016.

31. SligI WI, Eurich DT, Marrie TJ, Majumdar SR. Age still matters: prognosticating short- and long-term mortality for critically ill patients with pneumonia. Crit Care Med 2010; 38:2126-32.

32. Conte HA, Chen YT, Mehal W, Scinto JD, Quagliarello VJ. A prognostic rule for elderly patients admitted with community-acquired pneumonia. Am J Med 1999; 106:20-8

33. Calle A, Márquez MA, Arellano M, et al. Geriatric assessment and prognostic factors of mortality in very elderly patients with community-acquired pneumonia. Arch Bronconeumol 2014; 50:429-34.

34. Marrie TJ, Carriere KC, Jin Y, Johnson DH. Factors associated with death among adults $<55$ years of age hospitalized for community-acquired pneumonia. Clin Infect Dis 2003; 36:413-21.

35. Ewig S, Kleinfeld $T$, Bauer $T$, et al. Comparative validation of prognostic rules for community-acquired pneumonia in an elderly population. Eur Respir J 1999; 14:370-5.

36. Torres $\mathrm{OH}, \mathrm{Muñoz}$ J, Ruiz D, et al. Outcome predictors of pneumonia in elderly patients: importance of functional assessment. J Am Geriatr Soc 2004; 52:1603-9.

37. Marrie TJ. Community-acquired pneumonia in the elderly. Clin Infect Dis 2000; 31:1066-78.

38. Terraneo S, Polverino E, Cilloniz C, et al. Severity and outcomes of community acquired pneumonia in asthmatic patients. Respir Med 2014; 108:1713-22.

39. Liapikou A, Bakali D, Pantazopoulos I, et al. Community acquired pneumonia in asthma patients. Eur Respir J 2013; 42:P2720.

40. Leong LB, Jian KH, Vasu A, Seow E. Prospective study of patients with altered mental status: clinical features and outcome. Int J Emerg Med 2008; 1:179-82.

41. Janssens JP, Krause KH. Pneumonia in the very old. Lancet Infect Dis 2004; 4:112-24.

42. Corrales-Medina VF, Musher DM, Wells GA, et al. Cardiac complications in patients with community-acquired pneumonia: incidence, timing, risk factors, and association with short-term mortality. Circulation 2012; 125:773-81.

43. McFadden JP, Price RC, Eastwood HD, Briggs RS. Raised respiratory rate in elderly patients: a valuable physical sign. Br Med J (Clin Res Ed) 1982; 284:626-7.

44. Zhang ZX, Zhang W, Liu P, et al. Prognostic value of Pneumonia Severity Index, CURB-65, CRB-65, and procalcitonin in community-acquired pneumonia in Singapore. Proceedings of Singapore Healthcare 2015; 25:139-47.

45. Schuetz P, Koller M, Christ-Crain M, et al. Predicting mortality with pneumonia severity scores: importance of model recalibration to local settings. Epidemiol Infect 2008; 136:1628-37.

46. Abisheganaden J, Ding YY, Chong WF, et al. Health-care associated pneumonia (HCAP): identification of low and high-risk patients. Current Respiratory Medicine Reviews 2015; 11:241-6. 